\title{
Ghana's school feeding programme in perspective: A case study of the Akuapem North Municipality in the Eastern Region
}

\author{
*Samuel Okae-Adjei ${ }^{1}$, Buckman Akuffo ${ }^{1}$, Claudia Amartei ${ }^{2}$ \\ ${ }^{1}$ Koforidua Polytechnic, Koforidua, Ghana \\ ${ }_{2}^{2}$ Business School, Kwame Nkrumah University of Science and Technology, University post Office, Kumasi, Ghana \\ *yawsammy1964@yahoo.com
}

\begin{abstract}
This study identifies the successes and challenges of the Ghana School Feeding Programme (GSFP), and compares pre and post- academic performance of pupils in some selected schools in the Akuapem North Municipality of Ghana. Questionnaires and interviews were used to solicit information from respondents. The study revealed that the introduction of the GSFP in the Akuapem North Municipality has led to an increase in enrollment, retention and attendance of pupils in the beneficiary schools as well as improvement in the pupils' health status. However, there has not been any significant improvement in the academic performance of the pupils within the Municipality. The study recommends that efforts should be made by stakeholders to increase the number of teachers and expand the educational infrastructure to accommodate the increasing school enrollment.
\end{abstract}

Keywords: Akuapem North Municipality; Ghana School Feeding Programme; academic performance; community participation.

\section{Introduction}

In the year 2000, World Leaders met at the millennium summit of the United Nations to find a lasting solution to global development challenges. Out of the meeting came eight Millennium Development Goals (MDGs), which were aimed at reducing extreme hunger and poverty, to achieve universal primary education, equality of gender, women empowerment, among others (The Millennium Development Goals Report, 2014). In 2004 African Leaders spearheaded a radically new approach to social and economic development of Africa. In their bid to transform Africa and achieve the MDGs, a free basic education, a School Feeding Programme (SFP) and other strategic policies were adopted.

In Ghana, the School Feeding Programme (GSFP) was introduced in the year 2005 with the intermediate objective of reducing hunger and malnutrition; increasing school enrollment, retention and attendance and to boost local food production. The GSFP is to provide children in public primary schools and kindergartens in the poorest areas of the country with one hot, nutritious meal each day, prepared from locally grown food-stuffs (Abu-Bakr, 2008). The GSFP started with 10 pilot schools, selected from each region of the country. By August 2006, the number of schools had been increased to 200 covering about 69,000 pupils in 138 districts (GSFP Annual Operating Plan, 2007). Up to the year 2010, GSFP covered not more than 6 selected schools in each of the 170 districts, catering for over $1.040,000$ of the school pupils nationwide (Darko, 2014). This was in partnership with World Food Programme (WFP), Canadian International Development Agency (CIDA) and the Dutch Government. This was in a bid to fulfill the requirements of the Free Compulsory Universal Basic Education (FCUBE) and the MDG 1, 2 and 3 (Osei-Fosu, 2011).

After ten years of implementation of GSFP, little empirical evidence exists to show the effects of GSFP on the academic performance of pupils in the basic schools in Ghana (Abu-Bakr, 2008). It is therefore worthwhile investigating how the GSFP 
has affected pupils' academic performance. As noted, this study identifies the successes of the programme and compares pre and post- academic performance of pupils in some selected schools on the GSFP in the Akuapem North Municipality of Ghana.

\subsection{Overview of School Feeding Programmes (SFPs)}

According to Harper and Wells (2007), many countries in Europe had tried to introduce and implement SFPs to poor and hungry children. For example, Germany provided meals mainly made up of soup and potatoes and later expanded to include variety of meals. Harper and Wells (2007) elaborate on how England introduced the SFP especially to malnourished people and how the London Board and other private organizations with support from the Salvation Army helped in its expansion. The Netherlands became the first country to pass into law, school lunches in the beginning of the $20^{\text {th }}$ century to both public and private school children who were unable to attend school because of food (Kearney, 2013). In the case of Switzerland, school children were given lunches provided by NGOs (Gunderson, 2014).

In Africa, SFP was in practice as at the year 1940 (Bob, 2009). Countries such as South Africa supplied free milk to children. In Mali, SFP started in 1999 and was characterized by a wide community participation with the main objective to enroll and retain children in school, especially those in the districts and villages (Diallo, 2012). Varying reports from Uganda states that in 1997 Universal Primary Education Program (UPEP) was launched using Food- For- Education (FFE) to create access to primary school education in order to reduce hunger and also to attract vulnerable children to school (Korugyendo \& Benson, 2011).

SFP started in Ghana in the mid-20th century where pupils in a number of selected Catholic primary and middle schools benefitted from takehome rations across the country (Alhassan \& Alhassan, 2014). The main aim of the SFP was to increase enrollment of children as well as improving the nutritional status, which was in line with the social policy of the then Government to have wellqualified Ghanaian human resource base to fill job vacancies which would be left vacant after independence(Alhassan \& Alhassan, 2014). Accounts from Imoru (2010) indicate that SFP in the three Northern Regions of Ghana took the form of free meals being supplied to children in the boarding schools. In Sub-Saharan Africa, Ghana is said to be one of the ten countries that started with the SFP
(Mohammed \& Sakara, 2011) after the UN Millennium summit in 2000. As noted, the GSFP is being implemented as part of Ghana's effort towards meeting the United Nations MDGs 1, 2 and 3 which is spearheaded by the New Partnership for Africa's Development (NEPAD). The MDGs are to reduce hunger, attain universal primary education, and equality and empowerment of women (Ofoe, 2011). The Ministry of Local Government and Rural Development has the oversight responsibility for the GSFP. Collaborating partners of the GSFP include the Government of Ghana, World Food Programme (WFP), Netherlands Development Organization (SNV) and the Alliance for a Green Revolution in Africa (AGRA) (Graphic online.com, 2014). The GSFP has several stakeholders. These comprise District level stakeholders and school level stakeholders. At the District level, the District Implementation Committee (DIC) is made up of Ghana Health services (GHS), Ghana Education service (GES), District Assembly (DA), and the Ministry of Food and Agriculture (MOFA). At the school level, the School Implementation Committee (SIC) is made up of local Community members and school executives. The Ministry of Finance and Economic Planning is also a key stakeholder of the GSFP (Alhassan and Alhassan, 2014).

\subsection{Successes and challenges of SFPs}

Since the introduction and implementation of SFPs globally, a lot of successes have been achieved. As noted by Darko (2014, p.39) School feeding assists the "creation of job opportunities for skilled and semiskilled workers." Japan, Brazil, Chile, South Korea and the United States where the programme have been practiced for decades had witnessed major impact on the creation of jobs for local farmers, cooks and caterers. This has contributed to the rise of the Gross Domestic Product (GDP) and Per Capita Income (PCI) as well as the creation of a larger market for those countries”. Darko (2014) further observes that in Kenya, school meals have an impact on families by reducing the amount of money families spend to buy food which has automatically increased their savings for other purposes. In addition, parents use the time children are in school to work on a part time basis to earn extra money. Moreover, pupils who were underweight gained tremendously after weeks of good quality of food served whiles in school as well as being dewormed regularly. World Food Programme (2013) indicates that in Japan and Mexico, SFPs have gone a long ways to help solve obesity problems. Foods, which 
were low in calories and made up of vegetables and fruits as well as milk were basically executed on local preferences with the hiring of qualified nutritionists in the various schools.

It has been well documented in both developed and developing countries that school feeding with the right amount of quality ingredients have gone a long way to improve on pupil's performance. Badri (2014) explains how in the USA the school feeding has improved on pupil's academic performance, especially in mathematics and to some extent history based on the amount of calories in the food served them. From India, Harounan et al (2012) report that the national meal program saw an increment in girls' attendance and a slight increase in school enrollment. A study conducted in Burkina Faso shows increase in enrollment of girls due to the cereals take- home rations (WB, 2012). Highlighting a similar account from Mali, Hoof (2014) indicates that SFPs especially in the Northern part of Mali witnessed a significant percentage of student enrollment. SFPs enticed pupils to get to school early since they are served with food before classes commence.

From the Ghanaian perspective a lot of successes have been chalked as well. Arhin (2015) indicates that since the inception of the GSFP, public basic schools benefitting from the programme have recorded an appreciable increment in enrollment of pupils. According to Oduro-Ofori and YeboahGyapong (2014), the GSFP has reduced the level of primary School drop-out in the Kwaebibrim District in the Eastern Region since it serves as a motivational tool for primary children to stay in school. A study conducted on the GSFP in the GaruTempane District in Ghana revealed that the programme increased gross enrollment rate by $24 \%$ among participating schools but decreased by $7 \%$ in non-participating schools (Bukari \& Hajara, 2015 p.301). The Ghana News Agency (2014) observed an increment of pupils from 413,493 since the implementation of the GSFP in the year 2006/2007 to $1,739,352$ pupils in 2013/2014.

In sub-Saharan Africa, Ghana is said to be the first country to achieve the MDG goal on poverty reduction and hunger by the standard set by the United Nations (UN) in the Millennium development initiatives (GNA, 2013). The creation of jobs through the SFPs generated incomes to caterers and farmers to enable them feed their families.

In spite of the successes that SFPs have achieved, SFPs are saddled with many challenges. Every project needs a good budget and adequate financing. However, the SFPs in many developing countries are faced with financial constraints. Masina (2013) observes in a survey in Malawi that the SFP is under threat. This is as a result of insufficient funds to acquire more firewood due to the increment of enrolled children. In Namibia, Ellis (2012) indicates that individual households are required to supply firewood for cooking meals due to financial constraints. In the view of Ellis (2012), the situation is so bad that sometimes particular schools pay two bags of maize in exchange of firewood. Researchers believe that this practice is quite widespread. The National Coordinator for the GSFP attributed the financial challenges facing the GSFP to recent economic crises facing the country (Graphic online, 2013). This has made the release of money from the GSFP more difficult since the budget allocated to the program is too small. In Ghana the release of funds for the programme has been inconsistent. A delay in the release of feeding grants subsequently affects beneficiary pupils. The situation implies that caterers may not have access to funds to procure the needed items, cook and serve the beneficiary pupils. The delay in getting funds for caterers to cook has reduced the number of days meant for food to be served from five days to three days in a week (Kedze, 2013).

Evidences from schools on SFP shows that facilities for sanitation and hygiene are not up to the required standard. The Ghana News Agency (2013) reports, that the Karaga district in the Northern Ghana is well noted for poor sanitation in the discharge of the GSFP. It emphasizes lack of water and unhygienic practices among caterers and children as well. Due to political interference sometimes schools that need to be targeted are excluded from the GSFP. As indicated by Abu and Quaye (2012, p.8), "Political party favoritism within the school feeding programme remains a persistent challenge".

\section{Methodology}

The research adopted a mixed-method approach. Questionnaires and interviews were used to solicit information from the respondents. The target population of the study consisted of some stakeholders involved in the GSFP in the Akuapem North Municipality, namely the Municipal Implementation Committee (MIC) members, School Implementation Committee (SIC) members, Head teachers, Teachers, Parents and Pupils of the selected schools. Both probability and non-probability sampling techniques were adopted. For probability sampling, a simple random sampling technique was 
used while convenience and purposive sampling techniques were used for non-probability sampling. With 30 basic schools within the Municipality implementing the GSFP with an average of 8 teachers, including head teachers in each basic school, the researchers grouped the schools into five (5) clusters with six (6) schools in each cluster. Two (2) schools were selected randomly from each cluster giving a total of ten (10) schools within which the researchers administered questionnaires. These are Akropong Methodist Primary School, Tutu Primary School, Adawso Presbyterian Primary, Larteh Roman Catholic Primary and Krutuase M/A Primary. The rest are Bepowase Methodist Primary School, Asenema M/A Primary, Lakpa Presbyterian Primary School, Akropong Anglican Primary School and Tinkong Presbyterian Primary School. The clustering of the schools gave each school within the Municipality a fair chance to be selected. The researchers used a sample size of 100 , out of a total population of 240 teachers and head teachers in addition to other stakeholders in the various schools on the GSFP. The researchers administered 80 questionnaires to participants, which were made up of head teachers, teachers, a Municipal Implementation Committee member at the Municipal office and some School Implementation Committee members in the selected schools within the Municipality. Sixty (60) participants were also interviewed.
Both primary and secondary data were used to collect information on the GSFP in the Akuapem North Municipality. Interviews and questionnaires were used to collect primary data from MIC and SIC members, Head teachers, teachers, parents and pupils of the selected schools. Personal observation was also used by the researchers to gain first-hand information. A semi-structured questionnaire was used which had both closed and open-ended questions. The open-ended questions gave the researchers the opportunity to seek the opinions of MIC and SIC members, Head teachers and teachers on the GSFP and Pupils academic performance.

Face- to- face interviews were conducted for a member of MIC and some SIC members, parents and pupils on the GSFP and pupils academic performance. The researchers used local language in the interview in favor of respondents such as pupils and parents who were not fluent with the English language in order to express their opinions well. This allowed the researchers to gain in-depth information on the subject area. This was done with the use of an interview guide. The interview data was recorded with the permission of the respondents and later transcribed.

Tables 1 and 2 show the classification of respondents who completed questionnaires and interviewed respectively.

Table 1

Classification of respondents who were administered questionnaires, sample size and sampling technique used.

\begin{tabular}{ccc}
\hline Category of respondents & Number selected & Sampling technique \\
\hline Head teachers & 10 & Purposive \\
Teachers & 66 & Simple random \\
MIC & 1 & Purposive \\
SIC & 3 & Purposive \\
\hline Total & 80 & \\
\hline
\end{tabular}

Table 2

Classification of respondents who were interviewed and sampling technique used.

\begin{tabular}{lrl}
\hline MIC & 3 & Purposive \\
SIC & 9 & Simple random \\
Parents & 18 & Purposive \\
Pupils & 30 & Purposive \\
\hline Total & 60 & \\
\hline
\end{tabular}


The Statistical Package for Social Science (SPSS) IBM 20.0 was used to analyze the quantitative data collected by the researchers. The data were arranged in patterns and categories in order to interpret the responses from the questionnaires. This was done through the use of charts and graphs. The interpretation of the interview data was based on a cross comparative analysis. Conclusions were drawn from the analysis and some recommendations were given.

\section{Results and Discussion}

\subsection{The state of GSFP in the Akuapem North Municipality}

The researchers, in their quest to know how the various communities participate in the GSFP posed a question to that effect. Figure 1 shows the responses given by respondents.

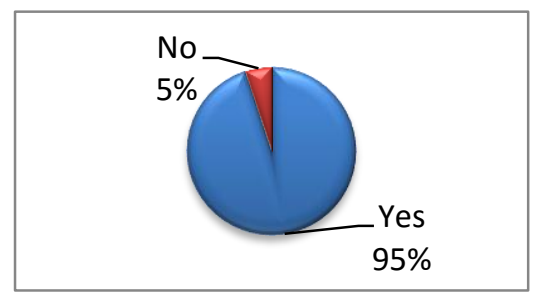

Fig. 1: Community participation in the GSFP in Akuapem North Municipality

From Figure 1, it can be stated that majority of the respondents (95\%) interviewed affirmed that their communities were involved in the implementation of the GSFP. However, a minority $(5 \%)$ were of the view that the community does not participate in the implementation of the GSFP. This implies there is high level publicity about the implementation of the programme in the selected area.

The researchers asked the various ways by which communities in which the case institutions are situated participate in the GSFP. The responses are as presented in Figure 2.

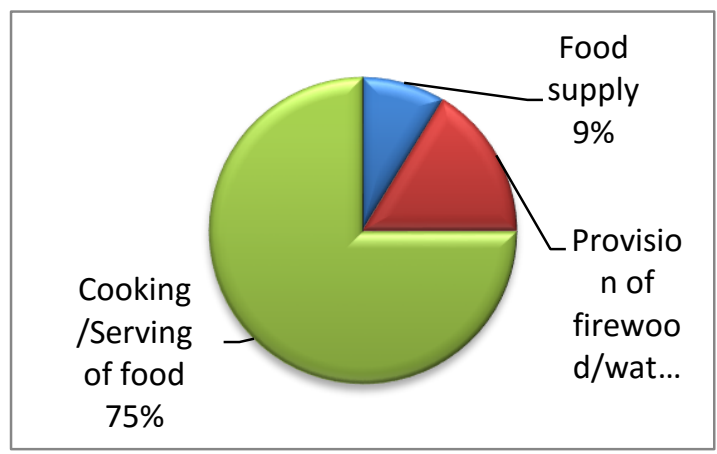

Fig. 2: Support being offered by communities to GSFP.
From Figure 2 it can be seen that, $8.75 \%$ said opinion leaders in the communities occasionally supply/donate food items such as maize, beans, 'gari' and red oil to support the GSFP in their respective communities. Whilst $16.25 \%$ respondents said that some of the inhabitants within the communities also provide firewood and water to the caterers to support the GSFP, 75\% indicated that, sometimes, some members within the communities assist in the cooking and serving of the food to the pupils. The implication of these results is that the community members are more interested in helping in the cooking and serving of food in the school. This can be attributed to the obvious benefits those serving may enjoy in the programme. It is also refreshing to note that there are some persons showing support by providing foodstuff to help sustain the programme.

The researchers were interested in knowing the level of knowledge of the respondents on how the GSFP is managed and implemented in the Akuapem North Municipality. Figure 3 shows the distribution of responses.

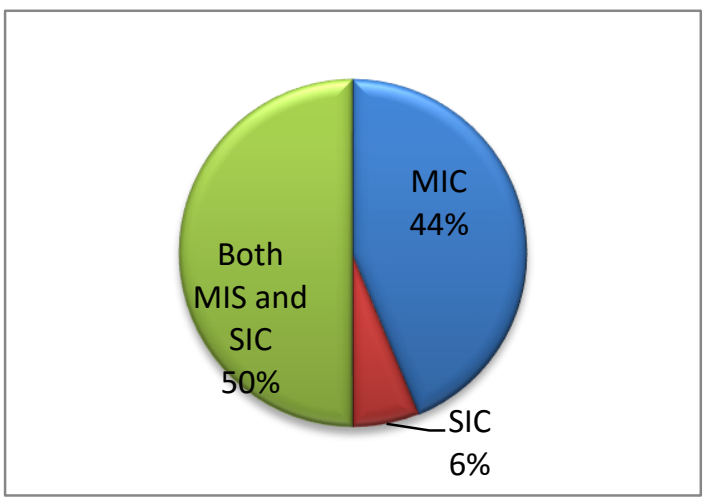

Fig. 3: Respondents view on management of GSFP in Akuapem South, Ghana

From Figure 3, it can be seen that respondents have fair knowledge on how GSFP is being managed in the study area. $44 \%$ respondents indicated that the Municipal Implementation Committee (MIC) is responsible for the implementation and management of the GSFP in the Municipality whilst 6.2\% said the School Implementation Committee (SIC) is responsible for the management and implementation of the GSFP in the various beneficiary schools. However, majority $(50 \%)$ of respondents stated that both the MIC and the SIC are the committees jointly responsible for the management and implementation of the GSFP in the selected schools.

Since the objective of the GSFP is to supply one meal in a day to school children within the academic year while increasing domestic/local food production, the researchers decided to find out the nature and type of meal served to the pupils of the 
selected beneficiary schools within the Akuapem North Municipality. This is to verify whether local foods are being served or otherwise. Table 3 shows the distribution of responses on the type of meals served in the schools.

Table 3

Type of popular meals served in the GSFP in Akuapem North Municipality

\begin{tabular}{lcc}
\hline Plain rice \& Stew & 18 & 23.00 \\
Waakye & 15 & 19.00 \\
Kenkey with hot pepper \& fish & 13 & 16.00 \\
Gari and Beans & 20 & 25.00 \\
Akple and Palm Nut Soup & 8 & 8.00 \\
Banku with Okro soup/Stew & 6 & 10.00 \\
\hline Total & 80 & 100 \\
\hline
\end{tabular}

Source: Field Survey, July 2015

From Table 3 it can be observed that a variety of food is being served on the programme. It is worth noting that $23 \%$ of participants (head teachers, teachers, MIC and SIC members) responded that the pupils are mostly served 'Plain rice' with stew, 19\% indicated that the pupils are mostly served with 'Waakye'. Additionally, 16\% respondents noted that 'Kenkey' with hot pepper and fish are also served to the pupils whilst $25 \%$ of respondents indicated that 'Gari' and beans with red palm oil, which is one of the popular local foods in the Municipality is served to the pupils. Moreover, $8 \%$ and $10 \%$ of respondents noted that the pupils are sometimes served with 'Akple' with palm nut soup and 'Banku' with okro soup respectively. The implication of the results is that even though the objective of the programme is to boost local food production, rice remains relatively high on the dining table of the schools. Is it the situation that we cannot do away with rice syndrome?

All the 18 parents within the communities with schools on the GSFP when interviewed affirmed that their children are given food at school as part of the GSFP. In the view of the parents, the GSFP is a good policy because it has taken some financial burdens off their shoulders such as the provision of lunch for the pupils at school. A major concern was however, raised by the parents interviewed regarding the quality and quantity of food served to the pupils. Personal observations made by the researchers at some of the case institutions showed that the quality, quantity and nutritional content of the food appeared not good enough. An interview with three (3) SIC members and the Desk Officer of the GSFP at the Municipal Assembly attested to this.

\subsection{The Successes of the GSFP in the Akuapem North Municipality}

The researchers were interested in finding out the general observation by stakeholders on the success or otherwise of the SFP in the Akuapem North Municipality. The respondents identified four (4) top factors per the introduction of the GSFP. Table 4 shows the distribution of responses given.

Table 4

General comments on the success of the GSFP in Akuapem North municipality

\begin{tabular}{lcc}
\hline Increase in enrollment & 21 & 26.00 \\
Regular school attendance & 12 & 15.00 \\
Improved health status & 39 & 49.00 \\
Improved academic performance & 8 & 10.00 \\
\hline Total & 80 & 100 \\
\hline Source: Field Survey, July 2015 & &
\end{tabular}


From Table 4 is can be seen that $26 \%$ of respondents (head teachers, teachers, MIC and SIC members) were of the view that the GSFP has led to an increase in enrolment and retention of pupils within the Akuapem North Municipality. Again, 15\% were of the view that the GSFP has contributed significantly to regular school attendance by pupils within the Municipality. Most of the respondents (49\%) believed that the health status of the pupils has also improved. This is because the pupils complain less of ill-health. However, only $10 \%$ saw an increase in the academic performance of the pupils in the Municipality. These responses were confirmed by the interviews conducted. All 18 parents interviewed indicated that the joy with which pupils now get themselves ready for school is amazing and applauded the government for such a wonderful social intervention.

The trend of enrollment at the Adawso Presbyterian Primary School before and after the introduction of the SFP is as presented in Figure 4.

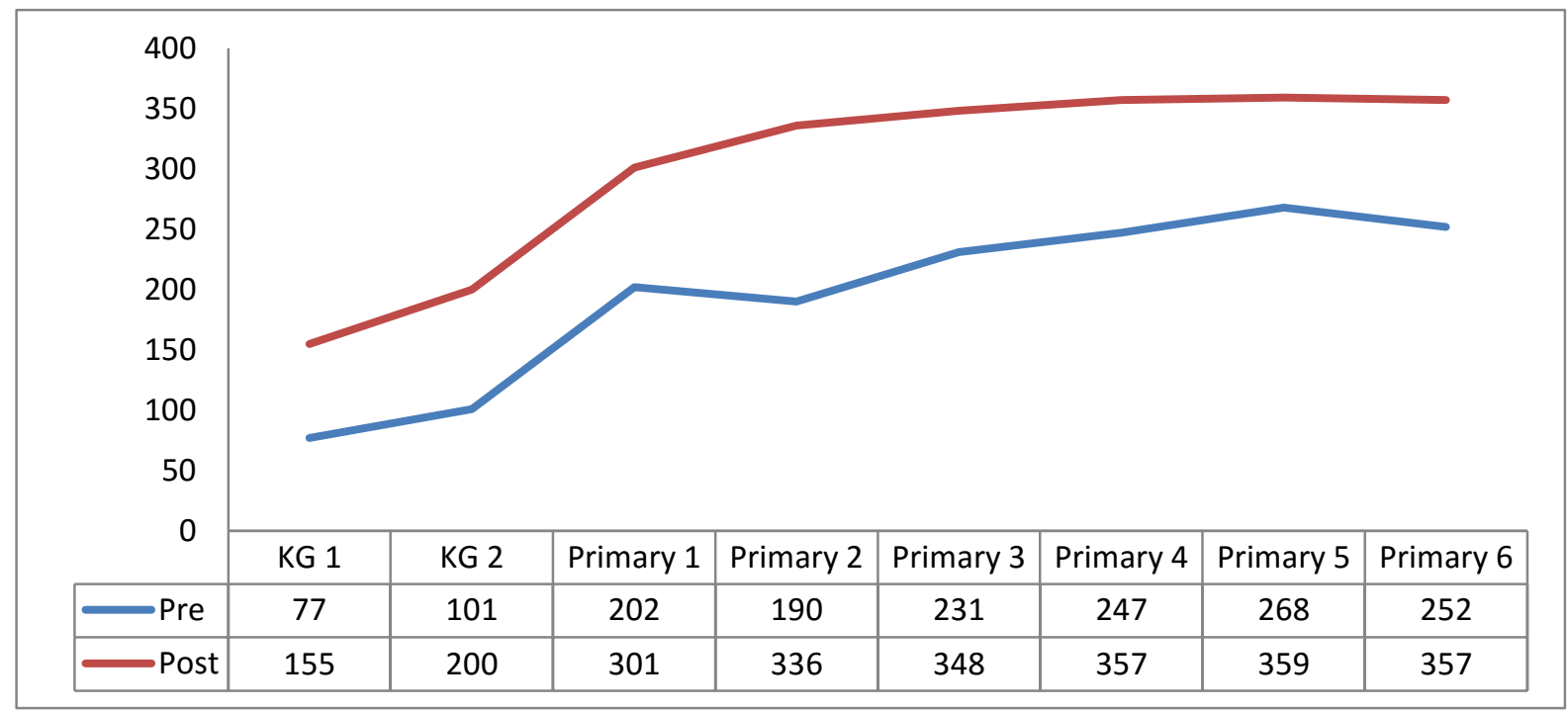

Fig. 4: The trend of enrollment at Adawso Presbyterian School before and after GSFP

The trend of enrollment at the Adawso Presbyterian School before and after GSFP as shown in Figure 4 indicates that there has been a significant increment in the enrollment of pupils as a result of the introduction of the GSFP. This is not different from the other selected schools.

On school attendance, interviews conducted with the SIC members of the selected schools revealed that, there has been a significant improvement in pupils' attendance to school and even punctuality. The researchers however, could not obtain any secondary data on attendance due to the reluctance of the head teachers to release the required data.

Interview with some health officials also revealed that the health status of pupils in the case study schools has improved. It was gathered that, apart from the nutritional meals served, the pupils are also dewormed once every term. This is done in collaboration and support from the Municipal assembly. Again, though health officials at the Tetteh Quarshie Memorial Hospital, Mampong Akuapem, were not ready to release data on the pupils to the researchers, it came to light that reported cases on meals related sicknesses have reduced significantly.

The researchers set up a hypothesis to test for the statistical significance of the pre and post enrollment figures at the selected schools as follows.

$H_{0}$ : average enrollment before and after the introduction of the school feeding programme is the same.

$H_{0}$ : average enrollment before and after the introduction of the school feeding programme is different.

The result is as presented in Table 5 . 
Table 5

t-test results on enrollment before and after the introduction of the school feeding programme in Akuapem North Municipality.

\begin{tabular}{cccc} 
& $\boldsymbol{T}$ & $\boldsymbol{d} . \boldsymbol{f}$. & Sig.(p-value) \\
\hline Pre \& post & -14.822 & 5 & 0.000 \\
\hline
\end{tabular}

The results from Table 5 imply we reject the null hypothesis and conclude that there exist a statistically significant difference between enrollments in the selected schools before and after the introduction and implementation of the school feeding programme at the Akuapem North Municipality in the Eastern region of Ghana.

\subsection{The pre and post-academic performances of pupils on the GSFP in the Akuapem North Municipality}

An interview conducted with teachers, parents and three SIC members on the contributions of GSFP towards the academic performance of pupils showed that, the introduction and implementation of the GSFP in the Akuapem North Municipality has not contributed significantly to the academic performance of the pupils in the beneficiary schools. A parent said "my child's performance is still the same though he attends class everyday". One member of the SIC at Tutu Presbyterian Primary School also said "nothing has changed much in respect of the academic performance of the pupils since the introduction of the School Feeding Programme in this school". Respondents were of the strong perception that the GSFP has indeed led to increase in enrolment, retention and attendance but not academic performance. Many believed that academic performance may improve over time but more needed to be added for this to be achieved. Some respondents interviewed maintained that the conditions of teachers also need attention, for teachers to get the satisfaction as the pupils for the total development of the academic potentials of pupils in the Municipality.

The researchers sought to evaluate the academic performance of pupils in the upper primary section to ascertain the academic performance of the pupils in English Language (Eng.), Mathematics(Math), Integrated Science (IntSci), Information and Communication Technology(ICT), three (3) years before and after the introduction of the SFP in the Akuapem North Municipality. The result is as presented in Table 6 .

Table 6

Average scores in selected subjects before and after the implementation of the SFP.

\begin{tabular}{lcccc|cccc}
\hline & \multicolumn{3}{c}{ Pre - GSFP Average Scores } & \multicolumn{5}{c}{ Post - GSFP Average Scores } \\
Primary 2 & 54 & 59 & 61 & 38 & 60 & 54 & 60 & 61 \\
Primary 3 & 65 & 56 & 62 & 41 & 61 & 61 & 62 & 63 \\
Primary 4 & 56 & 48 & 57 & 37 & 68 & 47 & 57 & 64 \\
Primary 5 & 49 & 38 & 44 & 43 & 56 & 51 & 55 & 52 \\
Primary 6 & 51 & 40 & 52 & 36 & 64 & 55 & 69 & 64 \\
\hline Total & 275 & 241 & 276 & 195 & 309 & 268 & 303 & 304 \\
\hline
\end{tabular}

Source: School's Statistics Records, 2015

A $\mathrm{t}$ - test conducted on the average scores in all the subjects before and after the implementation shows that there is no statistically significant difference $(p-$ value of 0.160 ) between the score obtained by the pupils before and after the implementation of the GSFP in the Akuapem North Municipality. This test collaborates the views expressed by the teachers and parents that the academic performance of the pupils has not improved much.

\subsection{Challenges of GSFP in the Akuapem North Municipality}

Despite the numerous successes that have been achieved by the GSFP in the Akuapem North Municipality, it has equally been bedeviled with some 
major challenges. Some of the challenges identified by the respondents are inadequate funding to support the programme, late release of funds to caterers, lack of transparency in the selection of caterers, quantity of food served is often too little, sanitation problems related to the environment in which the caterers prepare the food for the pupils and personal hygiene of the caterers. Others include lack of coordination and ineffective monitoring from the Municipal and School Implementation Committees and inadequate infrastructure resulting from increase in school enrolment, retention and attendance.

\section{Conclusions}

In their effort to transform Africa and achieve the Millennium Development Goals (MDGs), African countries adopted Free Basic education, SFP and other strategies. Ghana is no exception. Ghana introduced the Ghana School Feeding Program (GSFP) in the year 2005/2006. This was in partnership with World Food Programme (WFP), Canadian International Development Agency (CIDA) and the Dutch Government.

The study has produced insights into the nature of the GSFP particularly in selected schools in the Akuapem North Municipality, the successes of the programme in the Municipality, the pre and post academic performance of pupils on the GSFP in the selected institutions and the challenges facing the GSFP in the Municipality.

There is high community participation of the GSFP in the Akuapem North Municipality. Opinion leaders in the communities occasionally supply/donate food items such as maize, beans, 'gari' and red oil to support the GSFP in their respective communities. Sometimes some members within the communities assist in the cooking and serving of the food to the pupils. Pupils on the programme are served with traditional foods which are known to their respective communities. Both the MIC and the SIC are jointly responsible for the management and implementation of the GSFP in the selected schools. The GSFP supplies one meal in a day to school children within the academic year. It is worth noting that the introduction of the GSFP in the Akuapem North Municipality has led to an increase in school enrolment, retention and attendance of pupils in the beneficiary schools. It has also resulted in improvement of the health status of the pupils. However, there has not been any major improvement in the academic performance of the pupils which is as a result of GSFP within the Municipality. Some challenges faced by the GSFP in the Municipality include inadequate funds, lack of transparency in the award of contracts; late payment to caterers, quantity of food served is often too little, and sanitation problems related to the environment in which the caterers prepare the food for the pupils. To improve the GSFP in the Akuapem North Municipality, the researchers recommend that community participation in the GSFP should be further encouraged by the Municipal Assembly since the sustainability of every community based programme depends on how well the beneficiary community participates in such programmes. This will help in the long term sustainability of the GSFP in the Municipality. The GSFP and other relevant stakeholders such as the Ghana Government, Ghana Education Service and the Akuapem North Municipal Assembly should also put measures in place to build and expand the classrooms for the beneficiary schools. This is because the increase in enrollment of the pupils tends to be leading to overcrowding in the existing classrooms. More teachers should also be recruited. Again, the major Stakeholders of the GSFP in the Municipality should consider the quantity and nutritional content of the food given to the pupils to sustain the interest pupils have developed for school attendance.

\section{References}

Abu, A., and Quaye. W. (2012). Turning Challenges into Change: How Social Audits are Improving School Feeding in Sissala East, Ghana.

Afoakwa, Ohene., E. (n.d) The Home Grown school feeding programme. The Ghanaian. http:/www.gncf.org/library [Accessed 11.3.2015]

Alhassan, A., and Alhassan, F. (2014). An assessment of the operational challenges of The Ghana school feeding programme. The international Journal of Business and Management vol.2 issue 8. www.theijbm.com [Accessed 25.3.2015].

Arhin, B. G. (2015). Ghana Agriculture News Digest. School Feeding Programme. Available on line at; gssp:ifpri.info. [Accessed 11.3.2015]

Badri, Y.A. (2014): A review of the progress of school meal programs in the globe. Sky journal of food science vol. 3 (6) Available at skyjournals.org [Accessed 27.3.2015]

Bob, A. (2009): The African Bulletin. School Feeding in Africa: Ghana's success. Available on line at www.mediablackberry.com.

[Accessed 17.3.2015] 
Bukari, M., \& Hajara, I. P. N. (2015).The Ghana school feeding program: Factors affecting enrolment of pupils in Garu-Tempane district, Upper East Region. International Journal of Innovative Research and Development, 4 (1), 298-303.

Darko, B. (2014): The School Leadership views on the impact of the National school feeding programme in Ghana.[Accessed 5.5.2015]

Darko, B. (2014): The School Leadership views on the impact of the National School Feeding programme

Diallo, S.A. (2012): Evolution of school feeding in Mali. Available on line athttp://hgsf-global.org [Accessed 31.3.2015]

Ellis, J (2012): The Namibia School Feeding Programme: A Case Study. Available on line at http:/ documents.wfp.org [Accessed 14.4.2015] GSFP Annual Operating Plan, 2007

Ghana News Agency. (2014): Ghana School feeding Programme -using evidence for effective implementation. Available on line at http:/hgsf-global.org [Accessed 11.3.2015]

GNA (2013): Karaga District faces teething problems of the school feeding programme. available on line at www.modernghana.com [Accessed 30.3.2015]

Gunderson, G.W. (2014): National school Lunch Program, USDA. Available online at http:/www.fns.usda.gov/nsip/history

[Accessed 21.3.2015]

Harper, C. and Wells L (2007) School Meal Provision in England and Other Western Countries: A Review. School Food Trust UK

Harounan K, Damien de W, and Harold, A (2012) Educational and Child Labour Impacts of Two Food for Education Schemes: Evidence from a Randomized Trial in Rural Burkina Faso Available online at http://www.hkazianga.org/Ppapers/Kazianga deWalqueAldermanEducation.pdf [Accessed on 6.4 2015]

Hoof, K.v (2014) Mali: WFP Helps Get Children Back To School After ConflictAvailable on line at http://www.wfp.org/stories/mali [Accessed 25.3. 2015]

Imoru, A. (2010): Ghana school feeding programme, wobbles on in three Northern Regions. Available on line at http://rumnet.wordpress.com [Accessed 1.4.2015]

Kearney, J.E (n.d): Literature synthesis: School Feeding Programmes and Products, available on line at: http:/vut.netd.ac.za/jupu. [Accessed 23.3.2015]

Kedze, S. (2013): The Distortive Effects of Ghana's School Feeding Programme on
Primary Education Delivery: A case of Adentan Municipality. Available on line at: http://thesis.eur.nl/pub. [Accessed 23.3.2015] Korugyendo P, L \& Benson, T (2011) Food- forEducation programmes: Lessons for Uganda. International Food Policy Research Institute Policy. Note No. 13 Washington DC.

Masina, L. (2013): Malawi Primary schools plants tress to sustain school feeding program. Available on line at www.voanews.com/content/malawi

[Accessed 30.3.2015

Ministry of food and Agriculture. (2015): Available on line at http://mofa.gov.gh/site [Accessed 29.4.2015]

Mohammed, A and Sakara, F. (2011): Assessing Ghana School Feeding Programme on the enrollment of Beneficiary Schools in the Tamale Metropolitan Assembly of Northern Ghana, International Journal of Economics, commerce and Management, vol 11, issue 10. Available on line at http://ijecm.co.uk [Accessed 12.3.2015]

Oduro-Ofori, E and Yeboah-Gyapong A. (2014): The contribution of the Ghana School Feeding Program to Basic School Participation: A study of selected schools in the Kwaebibirim District of Ghana: Developing country studies, vol4, No.19. Available on line at [Accessed 21.3.2015]

Ofoe, D. (2011): Cost effectiveness analysis, selected programmes in Ghana's Education sector. Available on line at http://www.isodec.org [Accessed 11.3.2015]

Osei Fosu, A.K. (2011): Evaluating the impact of the capitation Grant and the School Feeding Programme on enrollment, Attandance and Retention in schools: The case of Weweso circuit, journal of science and Technology, vol, 3, No. 1, p55. Available on line at http://www.ajol.info/index [Accessed 3.3.2015]

The Ghana News Agency. (2014): Ghana school feeding programme holds learning event. Available on line at ww.ghananewsagency.org [Accessed 12.3.2015]

The Ghanaian Times. (2014): Lets salvage the school feeding program. Available on line at http:/lib.ohchr.org [Accessed 3.3.2015]

The Millennium Development Goals Report (2014): Available on line at http://www.un.org/millenniumgoals/2015 MDG [Accessed 12.3.2015]

Torson, S. (2013): An overview of the Ghana School Feeding Programme. Available online at http://sweetpotatoknowledge.org [Accessed 12.3.2015] 
UNICEF (2014): available on line at www.unicef.org/gambia/activities. [Accessed 27.3.2015]

WB (2012): Do School Feeding Programs belp Children? Available on line at http://siteresource.worldbank.org [Accessed 30.3.2015]

WFP (2012): Annual Report School feeding programme in poverty-prone Areas page 18. Available online at http:/www.icgbangladesh.org [Accessed 27.3.2015]

WFP (2014): School Feeding Programs: Why they should be scaled up. Available on line at http://www.unep.org [Accessed 1.4.2015]

WFP. School Meals. Available on line at: http://www.wfp.org [Accessed 21.3.2015]

World Bank and World Food Program: (2012]: Scaling up school feeding. Available on line at http:// siteresource.worldbank.org [Accessed 26.2.2015]

www.myghanaonline.com. . [Accessed 3.3.2015] 